\title{
An Investigative Study into the $C$. flumenia and its Interactions with its Surrounding Ecosystem
}

\author{
Sumer Sandhu' ${ }^{1}$, Aarav Sandhu ${ }^{1}$, Akshay Jakkidi Reddy ${ }^{2}$, Himanshu Wagh ${ }^{1}$ \\ ${ }^{1}$ California Northstate University, Rancho Cordova, USA \\ ${ }^{2}$ Department of Ophthalmology, California Northstate University, Rancho Cordova, USA
}

*Corresponding author: Himanshu Wagh, California Northstate University, Rancho Cordova, USA, Himanshu.Wagh5630@ cnsu.edu

\section{ABSTRACT}

Keywords

This research focused on the physical characteristics of Corbicula flumenia, an Cirri invasive species of clam found in the American River, and how these characteristics give it a possible survival advantage over native clam species of the river. Clams were collected from the American River and dissected, while river water and soil samples were also collected. The water and soil were analyzed for levels of coliforms such as Algae Clams E. coli, since this could be a food source that gives the Asian Clam an advantage over native species. The Asian clams were analyzed for their feeding efficiency of E. coli compared to algae and also compared for anatomical differences to the native species by measuring cirri size, which could increase feeding rates within these clams, giving them a competitive edge over their native competitors. It was found that there was much E. coli in the water and soil, but no significant correlation was found between clam cirri size and feeding rate. The Asian clam's DNA and protein expression was analyzed for genetic mutations that contribute to the species' invasive advantage.

\section{INTRODUCTION}

There are numerous examples in which species of organisms native to a certain geographical area have been outcompeted by species that are not native to that area (these species are known as "invasive"). For example, in Australia, the native species of toad have been outnumbered by cane toads (Bufo marinus), once introduced to the continent to decrease the population of sugar cane beetles, insects that were harming the Australian agricultural industry since they fed on sugar cane. A local example of an invasive species dominating a native species is the Asiatic clam (Corbicula Flumenia) dominating other native clam species in the American river in Folsom, California.

C. flumenia is a species of clam native to Southeast Asia and has succeeded in proliferating its population into several other waterways around the world, including 36 states across the United States and regions of northwestern Mexico. Studies have shown that, as a result of the high reproductive capability of C. Alumenia, it is able to increase its population size in a relatively short period of time [1]. This is one of the main reasons why this species has been so successful throughout the world and dominate native populations simply because native species cannot keep up with the reproductive rate of $\mathrm{C}$. flumenia populations. However, this is not the sole reason for the invasive advantage of C. Alumenia. In another study, it was found that the Asiatic clam had higher tolerance than expected to colder water temperatures than native species of clam, as some of these clams still survived in water temperatures close to $0^{\circ} \mathrm{C}$ [2]. These clams feed through filtration of the water around them, and high rates of filtration with production efficiencies of only 73-91 days (lower than average compared to other clam species) are another main reason for it being to outcompete its native competitor for food and nutrients from their environment [3]. With such a difference in physical traits between native clam species and the invasive Corbicula flumenia, it is clear why the native species of clam has been outcompeted by the Asiatic clam.

With the onslaught of heavy industrialization and a large shift towards fertilizer use in the agricultural industry, agricultural runoff and heavy-metal pollution of waterways serve as a 
challenge to the long-term survival and success of C. flumenia. A major food source for C. flumenia is algae, since these organisms are filter feeders. While algal growth tends to thrive at moderately high concentrations of agricultural pollutants such as nitrates and sulfates, it has been found that extremely high concentrations of nitrates and sulfates have been shown to negatively impact algal growth and have led to population declines of algae in various bodies of water across the world [4]. This could have larger implications on other marine organisms and, in particular, C. flumenia, as species which primarily feeds on algae. A decrease in algal population as a result of extremely high levels of pollution would deplete the primary food source and cause an overall threat to the very survival of the greater population of Asiatic clams.

Another concept worth investigating is the impact that heavymetal pollution of water has on the expression of the HSP70 protein within these clams, and how HSP70 expression could potentially harm the feeding efficiency of C. Alumenia. HSP70 is a stress protein that is expressed whenever the clam is stressed due to external disturbances. The magnitude of its expression is a direct indicator of the amount of external stress that the clam is facing. It can be hypothesized that greater levels of HSP70 expression correspond to a severe decrease in feeding efficiency, since high levels of stress would probably distract the clam from feeding as efficiently as it should.

This first portion of this lab will analyze the feeding rate of C. flumenia and the impacts that cirri size and the presence of outside disturbances such as noise and vibration had on its feeding patterns. The second portion of this lab will analyze the expression of the HSP70 stress protein within these clams in various environmental conditions by conducting a Western Blot Analysis. It is hypothesized that the presence of outside disturbances will cause the clam to exhibit stress and not feed as efficiently, and it is also hypothesized that HSP70 expression will be higher in an environment with higher sulfate concentration when compared to HSP70 expression in river water and lower sulfate concentrations. The following report will detail the methods used in this experiment, the data collected from said methods, and a discussion of the significance of the collected data.

\section{METHODS}

\section{Part 1. Field Collection}

To start this lab, teams of researchers went to the American river to collect three individual clams, soil, and water. After collection of clams, they were stored in water tanks at California Northstate University, and the water and soil samples were stored in the biology laboratory. The clams were kept there until later in the week for dissection, while water and soil samples were analyzed the following week.

\section{Part 2. Dissection}

The clams collected from the river were opened later in the week and dissected to obtain their individual gill and mantle tissues. Multiple samples were extracted and placed into various microcentrifuge tubes. Each tube was labeled according to its sample number and the identity of the tissue that was within the tube. Tubes labeled "A1", "A2", and "A3" each contained three individual samples of mantle tissue, while tubes labeled "B1", "B2", and "B3" each contained three individual samples of gill tissue. The mass of each gill and mantle tissue sample was recorded.

\section{Part 3. Data Analysis}

There is no data obtained from this part of the lab that could be analyzed. The purpose of this part of the lab was to collect clam samples that would come of use in later parts of the overall project.

\section{Bacteria Detection}

Samples of water and soil were collected from American River in two separate containers on the same day that the clams were collected. After properly mixing soil samples, 1000 microliters of soil were transferred to tube 1 and mixed well. 100 microliters of tube 1 soil were transferred to tube 2 containing 900 microliters of sterile water and mixed well. 100 microliters of tube 2 soil were transferred to tube 3 containing 900 microliters of sterile water and mixed well. Then, 100 microliters of contents from tubes 1,2 , and 3 were transferred to three new tubes and each were labeled " $10^{-1} "$, " $10^{-2}$ ", and " $10^{-3}$ ", respectively. A sterile swab was used to transfer the contents of each new tube to their respective agar plates, which were then placed in an incubator for a week to observe for number of colonies grown. Water collected was transferred to wells on a coliform plate, and the plate was transferred to an incubator for a week. The plate was then brought back to lab and placed on a white surface to count the number of blue wells showing (indicating number of coliforms present in a $100 \mathrm{~mL}$ sample of water). The plate was then placed in a dark room and placed under a UV light to count the number of glowing blue wells (indicating the number of $\mathrm{E}$. coli present in a $100 \mathrm{~mL}$ sample of river water. To get to these numbers, an MPN table was used. Much coliform bacteria were found in the water, and a good percentage of those coliforms were E. coli, as shown by the large percentage of glowing blue wells in the coliform plate. The fact that clams are able to thrive in such an environment indicates that they are thriving in an $E$. coli dominated environment. This could perhaps indicate that E. coli may be a potential food source for these clams. Also, the fact that several bacterial colonies were found in undiluted river soil indicates how successful clams are in an overall bacteriadominated environment, perhaps indicating that bacteria is key to their survival in some way. 


\section{Invertebrate Feeding}

The subject clams were exposed to E. coli as a food source, while the control clams were exposed to algae as a food source. Clams were either fed algae from a bottle or E. coli, and the change in absorbance over time was recorded for each of these two treatments by transferring samples of the water with $\mathrm{E}$. coli or algae into a coli plate well every 15 minutes. Following two hours of feeding, the coli plate was analyzed using a spectrophotometer to obtain data to construct a scatterplot that compares absorbance levels and time (change in absorbance over time). This change in absorbance gives an indication of how algae and E. coli concentration in the water in the presence of the clam changed, further indicating feeding rates of clams for these two treatments. A decrease in absorbance over time indicated that the clam was feeding regularly, while no change in absorbance over time indicated that the clam was not feeding significantly. The data collected showed that there was no significant feeding occurring in clams exposed to either E. coli or algae. This could be attributed to the large presence of outside noise and disturbances, which caused the clam to exhibit a stress response and not eat efficiently as a result.

\section{Cirri Spacing}

Samples of mantle tissue collected from earlier clam dissection were used to determine cirri spacing in clams. A software called "Image J" was used to determine cirri spacing size for each of the mantle tissue samples. This was done by first opening the clam to unveil the gill tissue, which was then extracted and placed under a microscope to get a clear image of the cirri itself. This image was then analyzed to find the average spacing between cirri using "ImageJ". Once the average cirri size was found, this measurement was compared with the rest of the class, and the average cirri size of each clam in class was recorded into a table. This table was used to generate a bar graph of individual average cirri sizes for each of the eight clams analyzed by all students in the lab section. Cirri spacing results give an indicator for feeding efficiency within clams. Class data was compared to individual data using standard deviation and error calculations. It was found that, on average, cirri sizes ranged from about 0.04 to $0.06 \mathrm{~mm}$, with no extremely low or high outliers. The standard deviation of around 0.003 was fairly constant for each of the eight clams of interest. Each of these cirri sizes were compared with the feeding rates obtained from the invertebrate feeding portion of this lab in order to determine a relationship between cirri size and feeding efficiency. For the clam of interest, since there was no clear feeding that occurred, not much of a relationship could be made between cirri size and feeding efficiency.

\section{DNA Barcoding}

In order to prepare the sample DNA for barcoding, $100 \mu \mathrm{L}$ of lysis buffer were added to the mantle tissue that was extracted earlier from sample clams and were subsequently grinded within the microcentrifuge tube using a pestle until the sample tissue was an almost-homogeneous solution. After this, the solution was incubated on a heat block for 50 minutes, after which it was immediately transferred to a $100^{\circ} \mathrm{C}$ heat block for 8 minutes. Following this heating, the tubes were subsequently centrifuged for 5 minutes at a rotational speed of 14,000 RPM. The supernatant was then carefully removed into two new respective tubes (S1 and S2), making sure not to disturb the pellet that formed at the bottom following centrifugation. 50 $\mu \mathrm{L}$ of silica resin were then transferred into each of these two tubes and mixed well for 30 seconds via pipetting. These two tubes were then centrifuged for 2 minutes at 14,000 RPM, and after centrifugation, the supernatant was removed and disposed of in the liquid waste container, making sure to not disturb the pellet that formed which contained the DNA of interest. $500 \mu \mathrm{L}$ of ice-cold wash buffer were placed into both tubes and were mixed well by vortexing. These mixtures were then centrifuged for one minute at 14,000 RPM, following which the wash buffer was added again and the mixtures were centrifuged were centrifuged again for one minute at 14,000 RPM. The supernatant was carefully removed from each tube and $100 \mu \mathrm{L}$ of sterile water were added to the washed pellets in both tubes. After heating the sample on a heat block for one minute and spinning the samples at 14,000 RPM for one minute, $90 \mu \mathrm{L}$ of supernatant from these tubes were transferred to two new tubes, labeled with group information, and stored at $4^{\circ} \mathrm{C}$ until the next lab period.

\section{Polymerized Chain Reaction}

In order to amplify the COI gene, PCR was conducted. This was done by first creating the Master Mix (MM) by mixing $180 \mu \mathrm{L}$ of $\mathrm{ddH}_{2} \mathrm{O}, 25 \mu \mathrm{L}$ of 10x PCR Buffer, $20 \mu \mathrm{L}$ of $10 \mathrm{mM}$ Primer Mix, $5 \mu \mathrm{L}$ of $10 \mathrm{x}$ dNTPs, and $5 \mu \mathrm{L}$ of Taq polymerase into a new 1.5 microcentrifuge tube. Four new PCR tubes were then obtained and labeled 1-4 with the group's initials, and $2 \mu \mathrm{L}$ of the sample prepared from the previous lab session were added into each of the respective tubes along with $48 \mu \mathrm{L}$ of master mix. The other two tubes served as a positive and negative control, respectively. All four PCR tubes were then placed on the thermocycler, whose settings were set to $94^{\circ} \mathrm{C}$ for one minute, $95^{\circ} \mathrm{C}$ for 30 seconds, $55^{\circ} \mathrm{C}$ for 30 seconds, and $68^{\circ} \mathrm{C}$ for 45 seconds (the previous three steps repeated in a cycle 35 times), and finally preserve the samples at $4^{\circ} \mathrm{C}$ following the 35 cycles.

\section{Gel Electrophoresis}

In order to start this part of the lab, agarose gel was prepared by adding $25 \mathrm{~mL}$ of $1 \%$ agarose gel to a casting tray and placing a gel comb inside the liquid gel, which was subsequently allowed to cool and solidify. While the gel was cooling, the samples to be loaded for gel electrophoresis were prepared by 


\section{Research Article}

adding $3 \mu \mathrm{L}$ of $6 \mathrm{X}$ EZ vision loading dye to both of the tubes labeled 1 and 2 (sample tubes), and $7.5 \mu \mathrm{L}$ of $\mathrm{ddH}_{2}$ and $3 \mu \mathrm{L}$ of loading dye to both of the tubes labeled 3 and 4 (positive and negative controls, respectively). Each tube had a total of 18 $\mu \mathrm{L}$ of contents within them, all of which were loaded into the gel following its solidification and removal of the gel comb. The gel, following placement into the gel rig and insertion of loading dye, was connected to a power source which was set to $100 \mathrm{~V}$ and allowed to run for half an hour. Following completion of electrophoresis, the current was stopped, and the gel removed and transferred to a UV transilluminator, which generated an image of the DNA bands on the gel for analysis. The sample that was sent out for sequencing was chosen based on this image, which can be seen as Figure 3A.

\section{PCR Sample Purification}

While the gel was running, the PCR product was purified by first transferring $65 \mu \mathrm{L}$ of the PCR sample to a new $1.5-\mathrm{mL}$ microcentrifuge tube, to which $325 \mu \mathrm{L}$ of Buffer PB was also added and subsequently mixed by vortexing. This sample was then transferred to a new QIA quick spin column tube in a 2-mL collection tube and centrifuged for one minute at 13,000 RPM. After discarding the flow-through and adding $750 \mu \mathrm{L}$ of PB Buffer to the tube, the sample was spun again at 13,000 RPM for one minute. The flow-through was again discarded and the 2-mL collection tube was placed back into the spin column, which was again sup for 30 seconds at 13,000 RPM. $30 \mu \mathrm{L}$ of sterile DI water were then added to the spin column and centrifuged a 13,000 RPM for one minute. The spin column was then discarded and the flow-through containing purified product was saved.

\section{COI Sequence Analysis using BLAST and Finch TV}

Once the samples that were sent out to be sequenced were returned, a computer analysis was conducted on the COI gene using computer software called BLAST and Finch TV in order to compare the sample COI gene sequence to the actual COI gene sequence of C. Alumenia. After using Finch TV to get a visual representation of the breakdown of the sequence (as shown in Figure 3C in the Results section of this report), this data was run through a BLAST search to find a $97 \%$ similarity between the sample COI gene sequence and the COI gene sequence of C. Alumenia that was obtained from the BLAST database. This shows that there are minor mutations in the sample clam collected from the river that cause the $3 \%$ difference between its $\mathrm{COI}$ gene sequence and the typical COI gene sequence of its species. This mutation could also be a potential cause for the irregular feeding rates seen from the invertebrate feeding lab, indicating that these mutations could be common among the $\mathrm{C}$. flumenia population of the American River.

\section{Protein Expression}

Mantle tissue samples were collected and placed on ice, and 1.5-mL Eppendorf tubes were obtained for each sample. Following this, $100 \mu \mathrm{L}$ of Buffer $\mathrm{K}$ solution were added to the sample, which was subsequently grinded using a pestle until it was an almost-homogeneous solution. These grinded tissue solutions were then transferred to three new $1.5-\mathrm{mL}$ Eppendorf tubes and labeled appropriately. These protein extracts were then taken to the fume hood and sample buffer was added to each of the protein extract on a 1:1 ratio with the mass of the tissue extracts. These samples were then inverted 2-3 times in order to properly mix and were subsequently placed on ice. The samples were boiled for 5 minutes in the heat block, following which the samples were immediately returned to ice. In order to begin this part of the lab, the tissue samples were first boiled at $95^{\circ} \mathrm{C}$ for 5 minutes. Following this, a tetra cell was set up by removing the ready-made BioRad gel from the storage pouch and gently removing the comb attached to it in order to reveal the gel wells. A gel rig was then obtained, and the gel was loaded by placing the first gel (short side facing inward) onto the gel frame and locking the green arms on either side of the rig over the gel. The inner chamber of the rig was then filled with running buffer, and once placed into a larger tank, the outer chamber was filled with running buffer as well. Once the gel rig was set up with running buffer, the samples were subsequently loaded in the following order: the first well with the $\mathrm{kDa}$ ladder, the second well with the positive control, the third well with the negative control, the fourth, fifth, and sixth wells with protein extract samples 1 , 2 , and 3, respectively, the seventh well with $0.1 \mathrm{mM} \mathrm{FeSO}_{4}$, and the eighth well with $0.5 \mathrm{mM} \mathrm{FeSO}_{4}$. The tetra cell was then plugged in and the power-source was set to $120 \mathrm{~V}$, and the gel electrophoresis was allowed to run for approximately 90 minutes. While waiting for the SDS-PAGE process to finish, preparations for the Western Blot portion of this lab were started. Once the SDS-PAGE gel run was completed, the gel rig was disassembled, and the running buffer was disposed of. The gel was cracked open and a plastic scraper was used to remove the lanes from the top of the gel. This gel was then placed in a cold $1 \mathrm{x}$ transfer buffer where it was subsequently activated with methanol. Within this container a gel transfer sandwich was assembled as follows: the black side of gel holder was at the bottom, followed by a pad, filter paper, gel, PVDF membrane, another filter paper, and another pad. Following the placement of these parts, a plastic scraper was used to remove any excess air bubbles, and the clear side of the gel holder was added to the top. The sandwich was then closed and placed into a gel rig with the black side of the gel facing the black side of the rig. The rig was then connected to a power source at a current of $100 \mathrm{~mA}$, and the blot was allowed to run for two hours. 
Following the Western blot, the PVDF membrane was removed from the rig and the TBST was poured out, the membrane was then washed with Ponceau S and the Ponceau $\mathrm{S}$ was subsequently drained out. The membrane was washed with TBST to have a clearer vision of the bands and remove background staining left by the Ponceau S. The blot for HSP70 was then obtained and the PVDF membrane was placed in a small bag along with the blot. The bag was then sealed and left on the shaker overnight. In the following lab session, the membrane was washed three times with TBST to remove excess background staining of the gel, and the blot was subsequently incubated in chemiluminescent substrate (allowing bands with target protein to glow according to where secondary antibody is bound). Once permitted by the instructor, the substrate was prepared by mixing $1 \mathrm{~mL}$ of ECL reagents with each other and adding the mixture to the membrane following draining of additional TBST that the membrane was kept in to avoid drying out. The membrane was then analyzed under a UV transilluminator to produce an image of glowing bands produced by the Western blot and the protein of interest, HSP70. The cropped image of the shining HSP70 proteins on the blot are shown in Figure 4A.
In the following lab session, the image obtained from the PVDF membrane following the Western blot and Immunoblotting procedures was analyzed using a computer software called "ImageJ" in order to quantitatively obtain the levels of HSP70 expression in each condition that was tested in the Western blot. Following cropping of the picture, selection of the appropriate bands based on the kDa Ladder and the known size of HSP70 $(70 \mathrm{kDa})$, and using the Magic Wand tool to find the area of certain curves generated from each band, the levels of HSP70 expression were quantified and summarized into a bar graph as shown in Figure 4B. It can be seen that exposure $0.5 \mathrm{mM}$ $\mathrm{FeSO}_{4}$ generated much higher levels of HSP70 expression than exposure to $0.1 \mathrm{mM} \mathrm{FeSO}_{4}$, showing the large direct effect that a higher concentration of environmental pollutants can have on HSP70 expression.

\section{RESULTS}

Figure 1A shows a scatterplot displaying the raw comparison of absorbance over time when sample $C$. flumenia clams were exposed to $E$. coli bacteria as a food source. Following the introduction of $E$. coli into the water, the absorbance of the solution containing the $E$. coli-water solution was measured
A

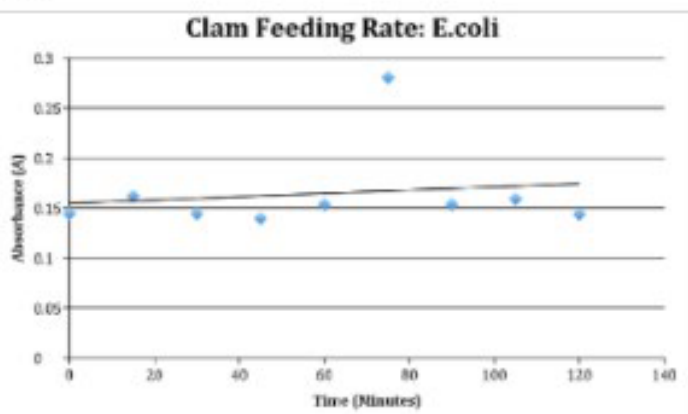

B

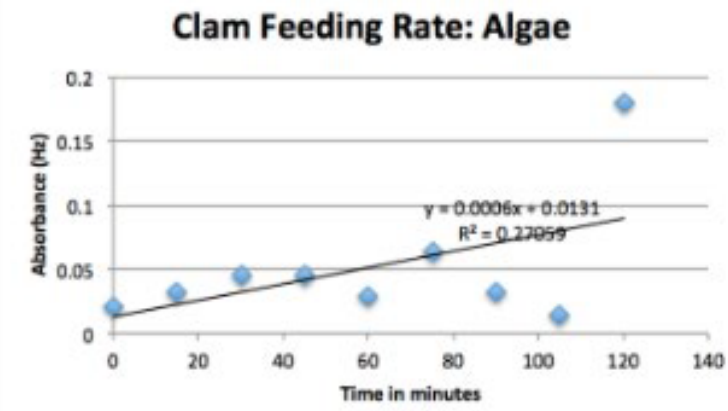

C

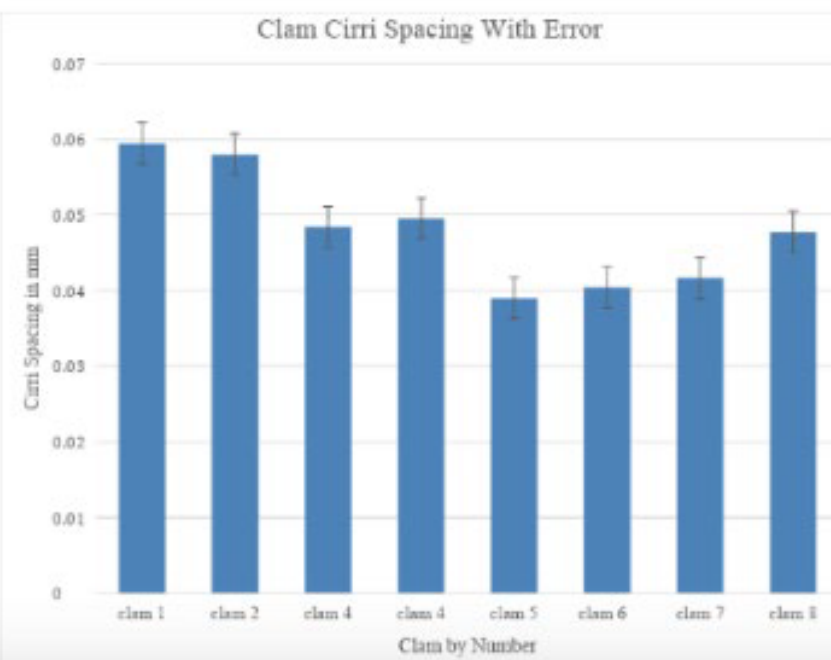

Figure 1. E. coli and Algae Feeding Rates of C. flumenia 


\section{Research Article}

at 20-minute intervals The change in absorbance over time is indicative of the change in $E$. coli concentration when exposed to the clam over time; a decrease in absorbance over time indicates that the clam is feeding on the E. coli food source, while no change in absorbance over time indicates that the clam is not efficiently feeding on the $E$. coli food source. The scatterplot shown as Figure 1A demonstrates how there was no clear change in $E$. coli concentration over time, showing inconsistent feeding of $E$. coli by the clams, which could be attributed to the presence of outside disturbances. Figure 1B shows a scatterplot displaying the raw comparison of absorbance over time when sample C. Alumenia clams were exposed to algae as a food source. The methods used to generate this graph were similar to those used to generate Figure 1A. From this part of the figure, it can be seen that there is, once again, no clear trend in feeding rate of $C$. flumenia when exposed to algae as a food source. The slight upward trend shown by the trendline is caused by one extremely high absorbance reading at time 120 seconds. Figure $1 \mathrm{C}$ displays the cirri spacing (with standard deviation) of each of the 8 clams from each lab group, which were all found through a software called "ImageJ". The greater the cirri spacing, the greater the general feeding efficiency of the clam. Clams 1 and 2 exhibited the greatest cirri sizes.

\section{Figure 1 Narrative}

The objective of this part of the experiment was to determine the feeding rates of C. flumenia when exposed to either clams or algae. This was done by having two tanks, both with a clam and water. One clam was exposed to algae as a food source, while the other clam was exposed to E. coli as a food source. Every 15 minutes, a sample of water from each tank were placed into different coliform plates for a total of two hours. After this duration of time, the coliform plates were taken to the spectrophotometer for analysis and data that ultimately gave the information necessary to plot an absorbance vs. time graph for each of the two food sources.

It was found that there was no significant feeding occurring for either food source, as shown by the lack of change in absorbance over time for both graphs. There was an extremely high outlier in both graphs causing the trend to go slightly upward due to mechanical error, however, there is no trend in reality.

Figure 2A shows the resulting petri dish and its bacterial growth following a $10^{-1}$ serial dilution of the soil solution collected from the American River. Figure 2B shows the resulting petri dish and its bacterial growth following a $10^{-2}$ serial dilution
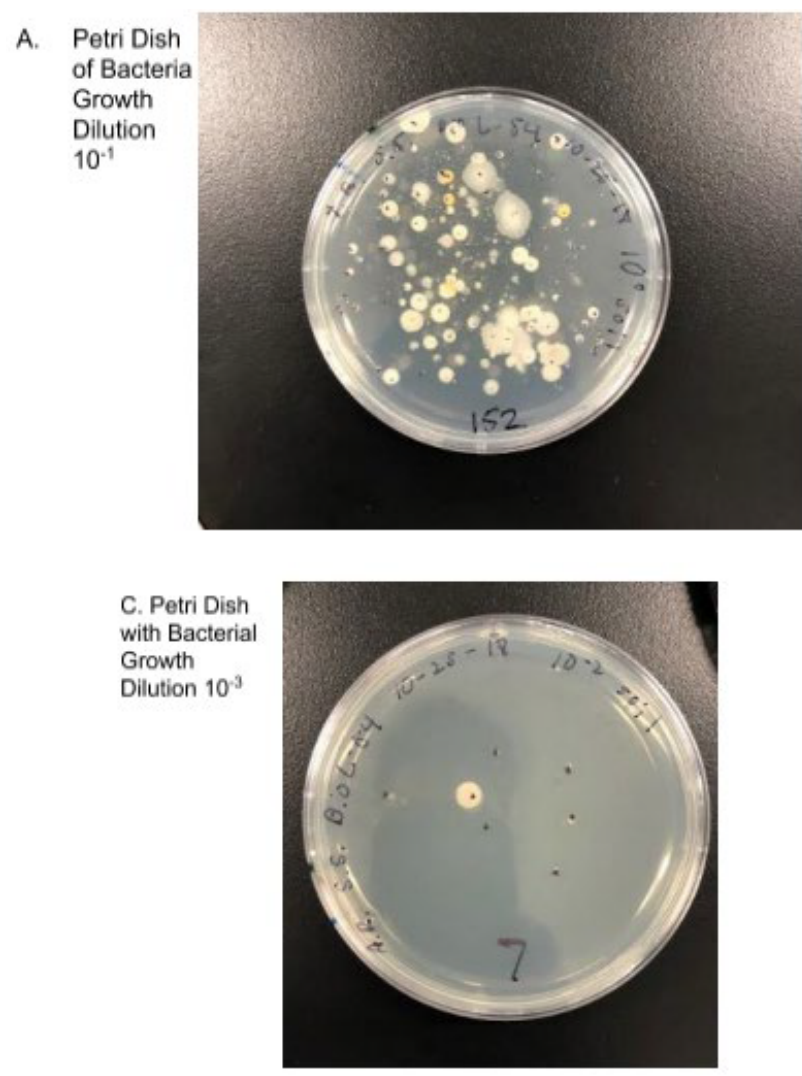
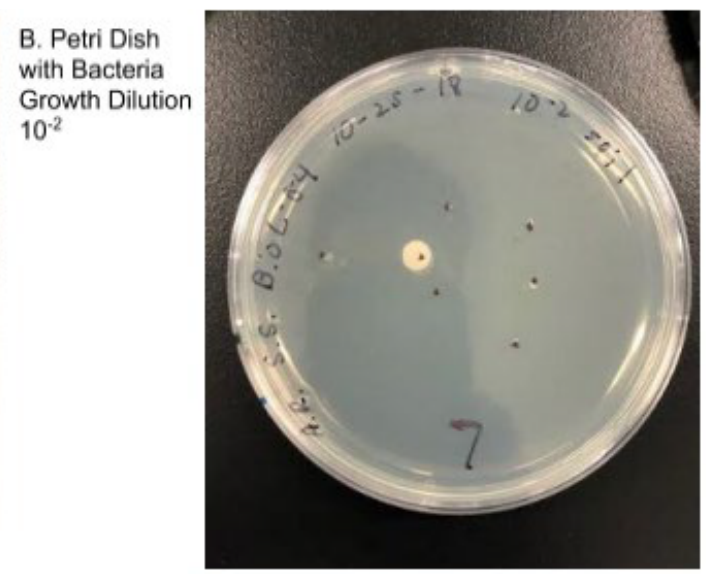

D.

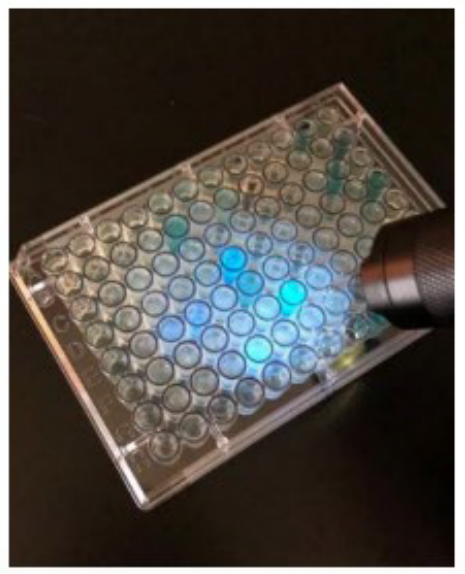

Figure 2. Results from Water and Soil Analysis for Presence of Coliforms 
of the soil solution collected from the American River. Figure $2 \mathrm{C}$ shows the resulting petri dish and its bacterial growth following a $10^{-3}$ serial dilution of the soil solution collected from the American River. For each of these three figures, the number of bacterial colonies detected on the plate is written as a large number near the bottom of the plate. The number of bacterial colonies seen following the $10^{-1}$ dilution was 152 colonies, while the number of colonies seen following $10^{-2}$ and $10^{-3}$ dilutions of soil were both found to be 7 colonies. Overall, the less diluted soil $\left(10^{-1}\right)$ exhibited formation of colonies that were larger and higher in quantity than the soil that was diluted to a greater extent $\left(10^{-2}\right.$ and $\left.10^{-3}\right)$. Figure $2 \mathrm{D}$ displays the coliform plate obtained from the water sample analysis portion of this part of the lab. It was found that 13 of the wells were blue (indicating the presence of coliforms), and 8 of those 13 wells were fluorescent blue under UV light (indicating the presence of $E$. coli).

\section{Figure 2 Narrative:}

The purpose of this part of the experiment was to analyze the soil and water of the American River for the presence of coliforms and E. coli. To do this experiment, samples of soil and water were collected from the American River. The soil samples underwent three serial dilutions, and bacterial growth on agar plates were recorded for each dilution. The water samples were separated to fill an entire 100-well coliform plate and incubated for a week to see the number of blue wells that appear (indicating number of coliforms), and how many of those blue wells turn fluorescent blue under UV light (indicating amount of E. coli).

It was found that of the 100 wells, 13 of them turned blue, while 8 of those 13 turned fluorescent blue under UV light, as seen in Figure 2D. This indicates that although there wasn't
A

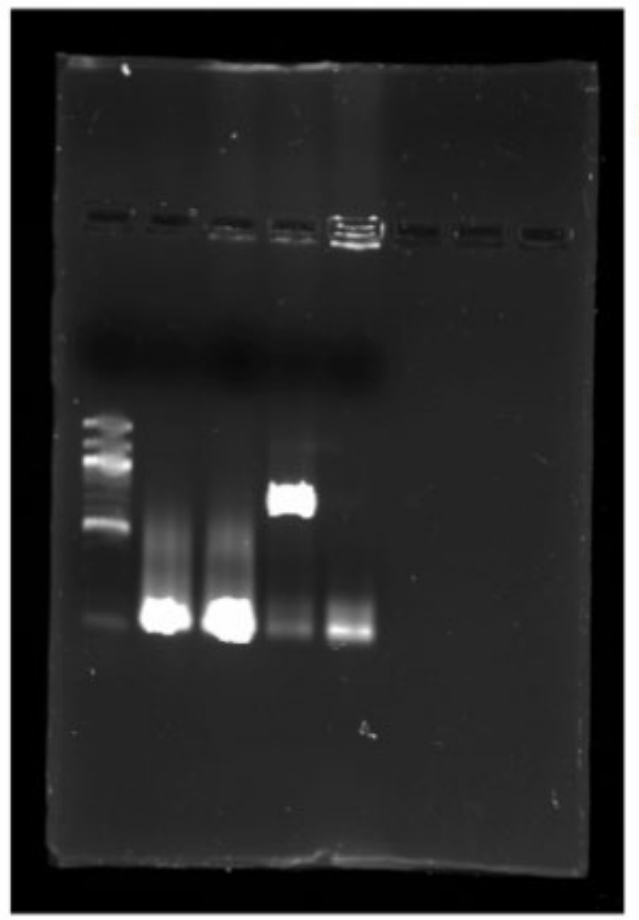

B

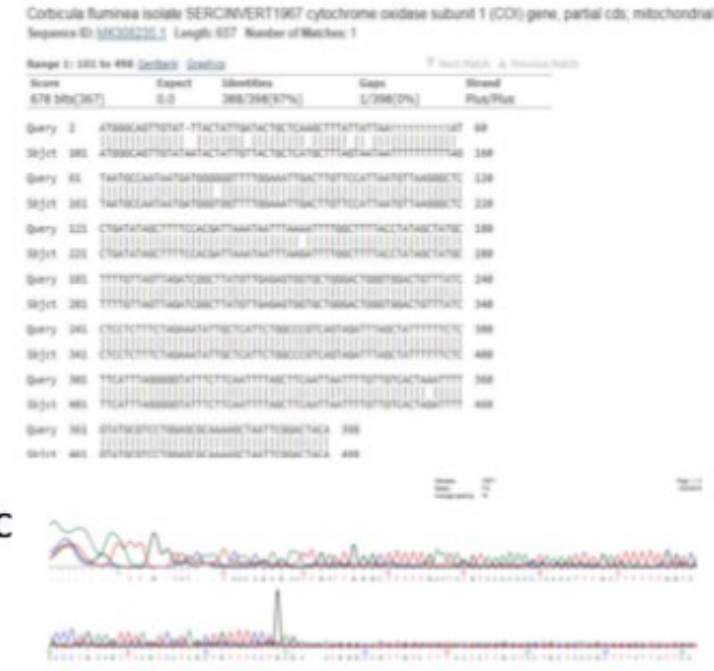

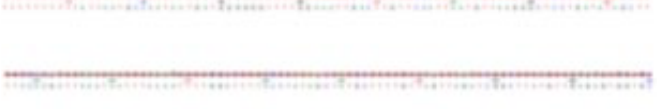
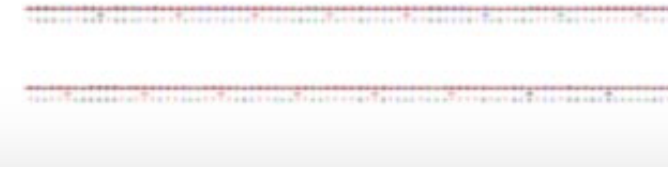

\begin{tabular}{l|l} 
Lane & Contents \\
\hline 1 (Left-most lane) & DNA Ladder \\
\hline 2 & Positive Control \\
\hline 3 & Negative Control \\
\hline 4 & PCR Sample 1 \\
\hline 5 (Right-most lane) & PCR Sample 2
\end{tabular}

Figure 3. Data Collected from COI Gene Analysis 


\section{Research Article}

a large coliform presence in the water, many of the coliforms found were E. coli. From the soil sample analysis, there was a large decline in the number and size colonies following a single dilution, as shown in Figures 2A, 2B, and 2C. This indicates a small coliform presence in the soil as well.

Figure 3A shows the agarose gel electrophoresis for the cut $C$. flumenia DNA. The first column from the left contains the KB DNA ladder, the second column contains the positive control (uncut DNA), the third column contains the negative control, the fourth column contains the first cut sample of DNA, and the fifth column contains the second cut sample of DNA. The farther the distance traveled downward from the top of the gel plate, the smaller the piece of DNA. Figure 3B displays the degree of similarity between the Forward Primer Sequence (the amplified COI gene) and the actual COI gene found on the BLAST database. The gaps in either nucleotide sequence represent nucleotides that were unrecognizable to the system. The "query" strand refers to the forward primer sequence obtained from DNA sequencing, while the "subject" strand refers to the actual COI gene of Corbicula flumenia. A 97\% similarity was found between the nucleotide sequences, with an E-value of 0.0 (found in the top row above the main table comparing individual nucleotides from both sequences). Figure $3 \mathrm{C}$ shows the progression and concentration of base pairs in the forward primer of the COI gene, as obtained from DNA sequencing. This was cut using a computer program to exclude regions that do not code for recognizable nucleotides and run through a BLAST search to be compared to the known COI gene nucleotide sequence for $C$. flumenia (same comparison as shown in Figure 3B).

\section{Figure 3 Narrative:}

The purpose of this part of the experiment was to analyze the level of similarity in the COI gene of the sample clam and that of the actual C. Alumenia obtained from the BLAST database. This was done by first isolating the COI gene from cells via cell lysis and heat shocking and analyzing the gene sequence using computer software such as BLAST and Finch TV. It was found that there was a $97 \%$ similarity between the sample gene and the actual COI gene of C. flumenia, as shown in Figure 2B.

Figure 4A displays a picture of the wells obtained following the Western Blot of the positive and negative control samples, clam samples 1,2, and 3, and $0.1 \mathrm{mM}$ and $0.5 \mathrm{mM}$ of $\mathrm{FeSO}_{4}$. This was conducted to identify the intensity of expression of HSP70 (a protein which is greatly expressed at higher stress levels) in these various conditions. The glowing of some bands indicates the presence of HSP70 protein within any given sample, since illuminescent tags were attached to the secondary antibodies that were used to identify the primary antibodies attached to the HSP70 proteins. The brighter the bands, the greater the expression of HSP70 for the given sample. The brightest bands were found in Sample 3 and $0.5 \mathrm{mM} \mathrm{FeSO}_{4}$,

\section{A}
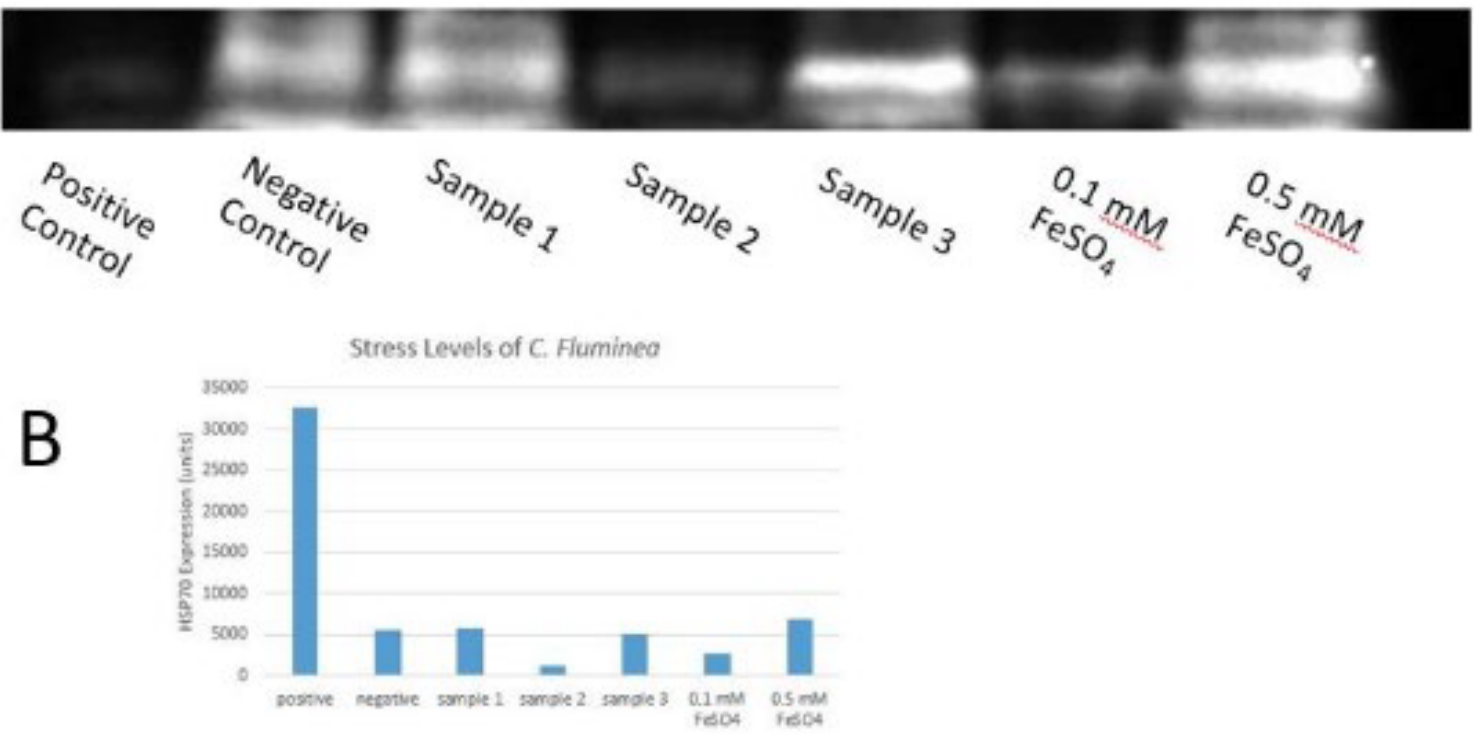

Figure 4. Stress Levels of $C$. flumenia Measured by the Expression of HSP70 Protein in Various Conditions 
as shown in this figure. Figure 4B displays the quantitative graph of HSP70 expression for each of the samples shown in Figure 4A. This quantitative analysis of the Western Blot was conducted using a software called "ImageJ", which generated the quantitative data required to create the bar graph shown in Figure 4B. A comparison of HSP70 expression in $0.1 \mathrm{mM}$ and $0.5 \mathrm{mM} \mathrm{FeSO}_{4}$ highlights a key finding that members of $C$. Flumenia experience much higher HSP70 expression (thereby higher levels of stress) when exposed to higher concentrations of sulfate. The fact that there was no shining band visible for the positive control in Figure 4A but there is a large HSP70 expression associated with it in Figure 4B.

\section{Figure 4 Narrative:}

The purpose of this part of the experiment was to analyze the HSP70 expression in various environmental stresses. This was done by first extracting the protein of interest from mantle tissue via cell lysis and heat shocking, and then identifying that protein of interest via Western blotting and Immunoblotting. It was found from this experiment that higher concentrations of pollutants such as iron (ii) sulfate lead to higher levels of HSP70 expression in the clams, thereby higher levels of stress.

\section{Scheme 1. Clam Tissue Cirri Size Standard Deviation of} Class Averages

$$
\sigma=\sqrt{\frac{\sum(\mathrm{x}-\text { mean })^{2}}{\mathrm{n}}}
$$

St. dev. $=\operatorname{sqrt}(0.001 / 7)=\mathbf{0 . 0 1 2 0}$

\section{Scheme 2. Sample Calculation for CFU/mL}

$\mathrm{CFU} / \mathrm{mL}=152$ colonies $/ 10^{-1}=1520 \mathrm{CFU} / \mathbf{m L}$

\section{DISCUSSION}

The purpose of this research was to explore the feeding rate of C. flumenia when exposed to algae and when exposed to E. coli, and how outside disturbances such as noise and vibrations affected the overall feeding efficiency of the Asiatic clams collected from the American River. The levels of HSP70 expression were tested within various environmental conditions, such as high-stress environments, low-stress environments, normal conditions, and environments with varying concentrations of iron sulfate $\left(\mathrm{FeSO}_{4}\right)$. From the clam-feeding portion of this lab, it was found that there was no noticeable feeding occurring when the clam was exposed to either algae or E. coli. This result can be explained by the fact that there was much outside disturbance occurring, such as loud noise and vibrations on the lab table, which caused the clam to exhibit high levels of stress and not feed at all. As a result, this part of the lab yielded significant results as it can be concluded that high levels of stress (leading to high levels of HSP70 expression) can lead to inefficient feeding or no feeding at all within the clam. From the Western Blot analysis portion of this lab summarized in Figure 2, it was found that the HSP70 expression of C. Alumenia in $0.5 \mathrm{mM}$ iron sulfate was much higher than the average HSP70 expression in 0.1 $\mathrm{mM}$ iron sulfate and in conditions of normal environmental stress, which are shown as samples 1, 2, and 3 in Figure 2.

When the results from both parts of this lab are combined, it can be seen that high concentrations of pollutants in the environment can lead to greater levels of environmental stress experienced by C. flumenia. In essence, it can be concluded that high levels of industrial pollutants in the water could negatively impact the feeding rate of the entire population of $\mathrm{C}$. flumenia to the point where its survivability as a species will be at risk as a result of non-efficient feeding. This result is crucial since C. flumenia depend on algae as their main source of food due to the fact that they are filter-feeders, and a decline in the abundance of algae as a result of high levels of water pollution would only further endanger the chances of C. Alumenia ability to survive in heavily-polluted environments.

The findings of this research project have agreed with previously conducted studies on the impact of high levels of pollution on the viability of the C. flumenia species. For example, a study analyzing the impacts of heavy metal pollutants on $\mathrm{C}$. flumenia found that high levels of heavy metal pollutants not only led to a rise in stress levels within the clams, but also delayed clam development and limited shell growth within adult clams [5]. This study is incredibly significant as it shows that the consequences of pollution are vast and thereby impact more than just stress-levels and rates of feeding within the Asiatic clam. For example, in a heavily polluted environment, an accumulation of developmental defects within the clam population could ultimately lead to competitive disadvantage for the C. flumenia, consequently leading to a decline in its survivability as a species. Another study found that the large presence of heavy-metal pollutants and pesticides have led to increased mortality rates of C. flumenia in various bodies of water [6]. As seen from this study, wide-scale industrial and agricultural pollution of bodies of water not only have an indirect effect on C. flumenia by impacting their stress levels, feeding rates, and development, but also have a direct effect on the survivability of members of this species as well. Thus, extremely high levels of pollution also serve to be a direct threat to the Asiatic clam species.

The aforementioned findings from this project are extremely important since they warn of the dangers of excessive pollution on marine ecosystems and, in particular, on the survival of $\mathrm{C}$. flumenia. While many view the Asiatic clam to be an invasive species that have negative impacts as a result of displacing native species of clam, its presence could eventually benefit the ecosystem in the long run when new species arise that 


\section{Research Article}

depend on C. flumenia as a vital part of the marine ecosystem. Ecosystems are constantly changing, and while this species of clam may seem like a nuisance as of now, it has the potential to become the central pillar of numerous marine ecosystems around the world.

There were several limitations to the study conducted. One of these limitations was mechanical error in measuring absorbance levels during the invertebrate feeding portion of this lab (refer to Figures $1 \mathrm{~A}$ and $1 \mathrm{~B}$ ). This mechanical error ultimately caused extremely high outliers in both the algae-feeding graph and E. coli-feeding graph comparing absorbance levels over time, which led to both trends appearing to go slightly upward when, in reality, there was no significant feeding occurring when the clams were exposed to either food source. Another limitation was the fact that only one heavy metal pollutant $\left(\mathrm{FeSO}_{4}\right)$ was tested for its impact on HSP70 expression in the Western Blot analysis portion of this lab. To accurately assess the impacts of heavy-metal pollutants in general on levels of HSP70 expression in C. Alumenia, more heavy metal pollutants (such as heavymetal solutions containing manganese and copper) could have been used. Yet another limitation was the need to conduct more trials within the invertebrate feeding lab to accurately determine whether or not outside disturbances that induced a stress response within the clams were the main reason that they were not able to feed efficiently when exposed to either food source.

Future research could be done on the consequences of other heavy-metal pollutants for the stress levels of C. flumenia and the impact that the presence of these metals directly has on its feeding rates. For example, a project could be set up in which clams are exposed to water with certain heavy-metal pollutants in it along with a potential food source (such as algae or E. coli). The absorbance of these solutions could be recorded over a certain time interval to check for how efficiently the clam feeds $n$ the presence of certain heavy-metal pollutants. Other future research ideas include the effect that industrial pollutants have on the survivability of other species of clam besides C. flumenia and the effect of industrial pollutants on shell quality and growth within various clam species.

\section{CONCLUSION}

In conclusion, the overarching purpose of this research is to test the impact of environmental pollutants on the HSP70 expression and stress response of C. Alumenia, and it was hypothesized that higher levels of HSP70 expression will result from higher concentrations of environmental pollutants, leading to further impacts such as inefficient feeding that could have detrimental effects on its survival as a species. The most important outcome of this experiment is that it shows how C. Alumenia are extremely sensitive to high levels of water pollution, as seen by the higher-than-average levels of HSP70 expression in the presence of higher concentrations of iron (ii) sulfate. These results are important since they show the harm that large-scale pollution can have on marine organisms, and why it is crucial that world governments take action in regulating levels of industrial and agricultural waste. Without a healthy marine ecosystem, society would not be able to survive since much of what we consume on a daily basis comes from the ocean and bodies of water across the world.

\section{REFERENCES}

1. Lopez-Soriano J, Quiñonero-Salgado S, Cappelletti C, Faccenda F, Ciutti F (2018) Advances in Oceanography and Limnology.

2. Li J, Rypel AL, Zhang SY, Luo YM, Hou G, et al. (2017) Freshwater Science, 36 (3), 595-608.

3. Deng Z, Sun S, Gao T, Han Z (2019) Animals, 9 (2), 36.

4. Sudhakar G, Jyothi B, Venkateswarlu V (1991) Metal pollution and its Impact on Algae in Flowing Waters in India. Archives of Environmental Contamination and Toxicology, 21 (4), 556-566.

5. Boltovskoy D, Correa N, Cataldo D, Stripeikis J, Tudino M (1997) Environmental stress on Corbicula fluminea (Bivalvia) in the ParanaÂ river delta (Argentina): Complex Pollution-Related Disruption of Population Structures. Archiv fuÈr Hydrobiologe, 138, 483-507.

6. Cataldo D, Colombo JC, Boltovskoy D, Bilos C, Landoni P (2001) Environmental toxicity assessment in the ParanaÂ river delta (Argentina): Simultaneous Evaluation of Selected Pollutants and Mortality rates of Corbicula Fluminea (Bivalvia) early juveniles. Environmental Pollution, 112, 379-389. 